\title{
Con tu sonrisa como bandera. Una mirada sobre el fallo dictado en el caso de Lucía Pérez
}

Isabel de Gracia ${ }^{1}$ Universidad Nacional de La Plata

Revista Derechos en Acción

Año 3/Nº 9 Primavera 2018, 471-479

DOl: https://doi.org/10.24215/25251678e234

ORCID: https://orcid.org/0000-0003-1951-5728

Salido de las cuevas más profundas del sistema patriarcal. Esa es la impresión que se tiene al leer el fallo por la muerte de Lucía Perez (1).

Y no cambia esa percepción el hecho de que tengamos por cierto que "la menor no tenía lesiones compatibles con abuso sexual, el cuerpo no fue lavado y es altamente probable que la muerte se debió (sic) a una intoxicación por el consumo de droga". Se descartan también las circunstancias fácticas (empalamiento y muerte por dolor) informadas por la primera fiscal interviniente en el caso. Todo esto ha sido dictaminado en forma unánime por los peritos, según se dice en la sentencia.

Porque lo que resulta interesante de analizar desde una mirada no experta (y aun indignada) no es tanto la absolución por abuso y homicidio en sí misma sino cómo se llega a ella. Es en el propio desarrollo metodológico, en la técnica judicial, en el abordaje de la cuestión que hacen los tres jueces del tribunal en lo criminal $\mathrm{N}^{\circ} 1$ de Mar del Plata donde se encuentra una de las formas más irritantes de manifestación del patriarcado.

¿Cuáles son los indicadores? ¿Qué es lo que permite hacer esta afirmación?

\footnotetext{
Abogada, integrante del Colectivo Tercer Piso, Fiscalía de Estado de la Provincia de Buenos Aires.
} 
"Asi he podido apreciar detalladamente los distintos chats...advirtiendo a partir de los mismos que fueron intercambios mutuos de información de datos personales (como edades, gustos musicales, personas con las que viven, actividades, etc.) que no demostraban ninguna circunstancia que hiciera presumir la manifestada ultra intención de someter sexualmente a nadie" (punto e. 3 del voto de Carnevale)

Tu vida nos pertenece: "¿Era Lucía una adolescente que podía ser fácilmente sometida a mantener relaciones sexuales sin su consentimiento?", a partir de esta pregunta y otras de similar falta de pertinencia para demostrar una violación, los jueces se apropian inescrupulosamente de la vida de Lucía. De sus conversaciones privadas, de sus costumbres, de su carácter, hasta de su léxico y ortografía adolescente. Su vida es descripta con lujo de detalles a través de testimonios y principalmente de sus conversaciones por chat. Respecto de los testimonios de las personas más cercanas en el afecto (madre, padre, hermano, amigxs), aparece la duda de si era necesario usarlos justamente para fundamentar la opinión de que acá no pasó nada (lo vemos como una consecuencia del abordaje elegido: poner el foco en la víctima). No podemos dejar de pensar que allí hay un primer acercamiento a la crueldad en forma de cinismo despreocupado.

Los chateos de Lucía ("prueba incontrastable" y "refractaria a interpretaciones especulativas", según los jueces) son analizados palabra por palabra. Como si la literalidad garantizara algo, como si no se pudiera mentir, engañar, exagerar y hablar "anfibológicamente" por escrito. El valor que le dan a este tipo de prueba es realmente perturbador. De esos mensajes se extraen varias conclusiones que no voy a comentar para no reproducir la violencia simbólica de la sentencia. En este sentido, resulta un desafío para la comunicación informar sobre algo humillante sin describirlo; pero se impone hacer el esfuerzo. Basta decir que los tres jueces deducen de los chats hábitos y características de la personalidad de Lucía y de allí dan por probado el presupuesto de hecho que lleva a la absolución: que no fue 
abusada, que no hubo asimetría en la relación con los adultos (“...de los chats analizados surge claramente que sus vivencias en este sentido alejan por completo la posibilidad de que hubiera sido sometida sin su voluntad" (sic) punto e. 2. del voto de Carnevale). Hay también un dictamen pericial, pero el abordaje patriarcal decanta gozosamente por el análisis de los chateos, que se diseccionan, se interpretan, y se transcriben durante todo el fallo, en una suerte de evocación -sin talento ni gracia- de los personajes chismosos de Manuel Puig. Ninguno de los jueces duda de estar habilitado no sólo para exponer la vida privada de la adolescente en una sentencia que será pública, sino en extraer obscenamente conclusiones de relevancia altísima (a su criterio) para la resolución de la causa a partir de interpretaciones totalmente subjetivas (y estamos hablando de tres subjetividades masculinas que parecieran tener cero capacidad de empatía, y hasta de conocimiento de lo que pasa en la calle). Si los jueces no saben lo que es cuidar la dignidad de una persona, nos preguntamos cómo podríamos esperar que juzguen adecuadamente a quienes -en el más leve de los casos- no cuidaron a la adolescente, al punto de facilitarle el consumo de drogas hasta desencadenar lo que suponen fue una "muerte por sobredosis".

En esa falta de cuidado por parte de los jueces, en esa apropiación depredadora, en ese "jugar a dios" es cuando vemos que empieza a desplegar su cola el pavo real del patriarcado.

“...olvidando el representante público justamente informar la culminación de ese chat donde [el imputado] le dice a su ex mujer 'te amo' "(voto de Viñas, el destacado pertenece al original)

Somos sororos nosotros: Llama la atención (permítaseme usar esta expresión tan criticada en la sentencia) que la actitud de los jueces haya sido "diametralmente opuesta" respecto de los varones involucrados en la causa. En relación a uno de los imputados (acusado de abuso) el juez opinante, criticando solapadamente al fiscal por tener que "recurrir a chats privados" (es decir, los mismos elementos probatorios de los que hicieron uso 
y abuso los jueces pero con relación a Lucía) recordó de pronto el artículo 19 de la Constitución nacional y se negó a analizar el historial de páginas porno en su computadora "ya que se tratan de situaciones de carácter íntimo que no constituyen prueba de cargo y que deben quedar exentas de la autoridad Judicial".

Incalificable el distinto tratamiento que se le da a la vida privada de varones (imputados) y mujer (víctima).

Frente a semejante muestra de violencia institucional, vemos casi como una nota de color o un comentario infantil (si no fuera por la trascendencia que les adjudican a sus propias opiniones) que el mismo juez considere que decir "te amo" en un chat descarte la intención de "cosificar" a las mujeres.

Aparece el mismo mecanismo de opacamiento de las cuestiones privadas masculinas cuando se menciona la "particular historia vital" de uno de los imputados como atenuante de la pena por el delito de comercialización de drogas. Sin embargo -y a pesar de su relevancia procesal- nunca nos enteramos de qué se trata esa historia. En este caso parece que no era necesario exponerla.

“...este último compró facturas y una Cindor para compartir con Lucía en su domicilio. Es evidente que estas actitudes no son las asumidas habitualmente por las personas con intención de cometer un hecho tan aberrante como por el que resulta acusado" (punto e. 4.1 del voto de Carnevale)

Ella sola, sin que nadie lo notara, se hundió: lo que más choca es que la exposición pública de la víctima se hace en el marco de un concepto de abuso que se desentiende de lo que cualquier persona medianamente informada viene viendo desarrollarse en la normativa y la bibliografía especializada, atravesada por una perspectiva de género y de niñez. Si este fallo quedara firme nunca sabríamos qué fue realmente lo que pasó porque las preguntas que disparan la argumentación de los jueces son tan sesgadas e impertinentes que dejan fuera un cúmulo de situaciones que bien podrían encuadrar como abuso u homicidio. 
De esta manera, el fallo no se hace lugar para analizar si -la facilitación del consumo de droga -a una adolescente de 16 años- por parte de un mayor -que vende estupefacientes a menores- y tiene relaciones sexuales con ella -hasta que muere de una sobredosis- no resultan de por sí elementos suficientes para demostrar la situación de vulnerabilidad de Lucía y el dolo eventual. Dicen los jueces que esta actitud del imputado es "espantosa", "deleznable", "repudiable" pero que sin embargo "no reviste calidad de delito". No he encontrado en la sentencia ninguna cita de normas relacionadas con los derechos de niños, niñas y adolescentes.

Por lo contrario, se dice - "sin ánimo de juzgar", por supuesto- que Lucía "no se mostraba como una chica de su edad". ¿Quiere decir que no tenía 16 años? ¿Quiere decir que no murió a los 16 años? No hace falta conocer las leyes para sentir que si fuera una hija nuestra pensaríamos que murió en una situación que por su edad la sobrepasaba, y de hecho la sobrepasó. Pareciera que los jueces, más afectados que "la sociedad" por las palabras de la fiscal, hubieran puesto todo su empeño en demostrar que no hubo un típico crimen de género y se hubieran olvidado de que esa chica además de mujer era casi una niña (vulnerabilidad al cuadrado). Y vuelvo a repetir, no lo digo por la absolución, sino por el tratamiento que le dan al caso. Porque en lo personal no acuerdo con la "expansión punitivista", ni el "castigo ejemplar", ni el linchamiento mediático, ni la condena social por portación de rostro, ni el juzgamiento implacable y apresurado de ciertos destinos juveniles que caen en el delito, y la cárcel me parece una institución infausta, pero pienso que ese tratamiento reduccionista que han hecho de la causa ha impedido (aun más que la "fiscal natural") que se haga justicia y, en su caso, que se absuelva a los imputados luego de agotar todas las hipótesis, no sólo las que se relacionan con un concepto de vulnerabilidad, abuso y desequilibrio de poder que atrasa 50 años.

Porque llama la atención (disculpas de nuevo) que habiendo pergeñado tantos links altamente bizarros (entre el mate y el 
sexo no consentido, entre la personalidad de una mujer y una supuesta inmunidad contra los abusos, entre los chateos y la verdad) los jueces no hayan considerado la posibilidad de que hubiera una relación entre la edad de la víctima y su situación de vulnerabilidad, entre su condición de "habitué al consumo de sustancias" y su dependencia de los proveedores (la propia sentencia menciona un intento de abuso anterior en ese marco), entre el escenario que facilitó el lamentable desenlace y el rol que allí desempeñaron los imputados, entre el estado de inconsciencia por consumo excesivo y la posibilidad de un abuso, entre la causa de muerte y la ocupación del imputado principal. En el fallo, esta falta de exploración de hipótesis que a la primera vista de cualquiera hubieran sido las más aceptables, aparece como una deuda que ojalá sea subsanada en otra instancia.

“...y la connotación de [el imputado] se enfocó [solo] en tomar unos mates” (punto 5.2. del voto de Gomez Urso)

La culpa es de la otra: como si estuvieran viviendo en una burbuja donde no pasa nada (esa es la impresión) adjudican el reclamo de justicia (de un "castigo ejemplar" dicen ellos con sus propias y arcaicas palabras, sin advertir que el feminismo también es "insumiso" y pone en cuestión el punitivismo que surge de la estructura paternalista de los poderes públicos y sus instituciones jerárquicas) exclusivamente al impacto producido por los dichos de la fiscal. Qué simplista esa mirada sobre el movimiento de mujeres, qué reducido el ángulo de observación sobre lo que pasa en la realidad. Como si las palabras (fuertes, dolorosas, dicen que inexactas) de la fiscal hubieran traccionado sobre la nada misma, sobre un estado de situación de bienestar para las mujeres donde no ocurre un femicidio cada día y medio. Como si la indignación acumulada (que desató el primer paro de mujeres) fuera casual y no hubiera podido surgir con el caso anterior o con el próximo, como si resultara improbable que una mujer pudiera morir asesinada por empalamiento, o como si fuera necesaria semejante saña para lamentar la pérdida de la vida de una adolescente No fue la 
fiscal "la que movió un país", fue el genocidio en cuentagotas que produce el sistema patriarcal.

El aislamiento contextual de las palabras de la fiscal (tan duramente criticada en la sentencia que no hace falta reiterarlo) y la suposición de que el reclamo de justicia se ata únicamente a ese hecho puntual, revelan un desconocimiento y una subestimación del movimiento feminista a niveles no ya preocupantes, porque estamos preocupadas hace tiempo aunque el poder judicial no esté enterado, sino alarmantes (hay que reconocer que quizá si los jueces tuvieran menos poder de decisión el problema sería menor). Acá, según los sentenciantes, la fiscal tiene la culpa de la movilización popular y la propia víctima de 16 años de la exposición al peligro y la sobredosis. Pareciera que los únicos que son capaces de salir indemnes del complejo entramado de la realidad y los laberintos estatales fueran sólo los tres jueces.

"..lo cierto es que ella habia arreglado un encuentro donde iba a verse con [el imputado] a solas y lo de la rapidez o fue una excusa o una errónea apreciación del testigo porque una cita que incluiría mates y facturas (chat \#73, dia 8 de octubre de 2016, 8:43:43 a.m.) difícilmente sería tan breve." (punto e.3 del voto de Carnevale)

Nada escapa a nuestro intelecto: los jueces coronan la mirada patriarcal sobre el caso diciendo que ellos "no desconocen la existencia de la llamada violencia de género". Dejemos de lado la formulación de la frase, que pone más dudas que certezas sobre la llamada "absoluta consciencia" que tienen de la cuestión. Lo que quieren es seguir blindando su sentencia. Qué desparpajo. No basta citar tres o cuatro convenciones internacionales y dos o tres causas donde ese mismo tribunal condenó a un femicida para demostrar que saben de qué se trata la violencia hacia las mujeres. Todo el abordaje del caso para llegar a la conclusión final desmiente -muy a pesar de ellos- esa afirmación.

Repasemos: sensibilidad disminuida, exposición innecesaria de la vida privada y falta de cuidado de la adolescente, revictimización, utilización de categorías de análisis arcaicas, 
arbitrarias y estigmatizantes, apropiación simbólica de cuerpos y territorios ajenos, uso de chivos expiatorios para desviar la atención, subestimación de las movilizaciones de mujeres y del gravísimo estado de situación, asertividad androcéntrica en grado superlativo, autocomplacencia (nuevamente dejamos afuera a la absolución).

Este derrotero a los tropezones incluye todo tipo de descalificaciones e instrucciones hacia los demás ("impresentable" le dicen al eviscerador, "irreflexiva y poco profesional" a la perito, "insensata, imprudente e irresponsable" a la primera fiscal, que actuó "pour la galerie" al fiscal actual, que "evidentemente formó un preconcepto del que a todo el mundo le cuesta despojarse" a una representante del Consejo de la mujer (así valoraron a la persona que fue a "ilustrarlos" sobre violencia de género), que "no estuvieron a la altura de las circunstancias" a los operadores que forman parte del sistema penal, que están "regidos por la política y no por la ley" a quienes no queden conforme con la sentencia, que se dejaron arrastrar "por una bola de nieve" a los grupos de derechos humanos, que deberían realizar "un proceso psicológico de aceptación" y recibir la nueva perspectiva judicial "con beneplácito" a los padres y el hermano de Lucía. Y paralelamente desarrollan un largo repertorio de halagos entre ellos mismos y su propia tarea, a la que califican de "detallada", "razonada", "certera", "íntegra”, "pormenorizada", "meticulosa", "prolija”, "precisa", "valiosa", "exhaustiva".

¿Es posible ser tan perfecto dentro de un sistema tan defectuoso? La pregunta no lleva sarcasmo, sino apenas la intención de buscar visibilizar la omnipotencia que tiene implícito ese lugar de enunciación de los operadores del patriarcado.

Es que se trata de una sentencia didáctica y "muy clara" en ese sentido porque desnuda el funcionamiento de las cabezas que sostienen el sistema patriarcal. Con una ingenuidad que posiblemente derive de la impunidad que han usufructuado durante siglos, los tres jueces nos muestran, sin siquiera darse cuenta, o quizá creyendo incluso que están del otro lado del 
mostrador, cómo funciona por dentro la usina de atropello de dignidades. Estas licencias son privilegios que ya no resultan admisibles en este siglo XXI y menos en funcionarios públicos. Nadie sabe todo. Todxs hemos sido educadxs dentro del sistema. Si los jueces no están capacitados en cuestiones de género y estuvieran genuinamente interesados en modificar esa condición, pueden estudiar, formarse, pedir asesoramiento y ayuda, o por lo menos hacer leer la sentencia por una especialista antes de darla a conocer. No hace falta simular lo que no se es. Este sinceramiento sería un gran aporte para empezar a pensar un mundo donde podamos vivir bien. No se va a caer nada importante, salvo el patriarcado. 